\title{
Follow-up Evaluation of Environmental Impact for Baicheng Industrial Park Planning
}

\author{
Li Jian-jia \\ Yingkou Environmental Assessment Co., Ltd \\ Yingkou, Liaoning, China
}

Zhuang Zhong

School of Environmental Science

Northeast Normal University

Changchun, Jilin, China

\author{
Cui Peng \\ School of Environmental Science \\ Northeast Normal University \\ Changchun, Jilin, China \\ Sun Shi-jun ${ }^{*}$ \\ School of Environmental Science \\ Northeast Normal University \\ Changchun, Jilin, China \\ (Corresponding Author) sunsj763@nenu.edu.cn
}

\begin{abstract}
This article takes the planning for Baicheng Industrial Park for the main object. Starting from the theoretical research, the paper conducts a deep investigation and analysis of the actual development of the Baicheng Industrial Park. With the method system of qualitative and quantitative analysis, the paper establishes and analyzes the planning environmental impact tracking evaluation method adapted to the Baicheng Industrial Park. By the prediction of pollutants at the present stage and comparison with the original planning, the paper proposes detail adjustments for subsequent development of the Industrial Park. Comparing with other evaluation methods, the evaluation process is not nuanced, but it does have a strong practical value.
\end{abstract}

Keywords: Planning Environmental Impact Assessment; Baicheng Industrial Park; following assessment; assessment procedure

\section{INTRODUCTION}

In recent years, with the improvement of the national economy and industrial development, industrial clusters have present ascendant trend. However, there are many uncertainties and variability in the process of implementing, which will inevitably cause certain impact on the environment. At present our country only conducts environmental impact assessment during the beginning of the planning construction [1]. However, large-scale industrial park development lasts longer and wider effects than singer project. So it is necessary to plan further environmental impact assessment (i.e., the track planning environmental impact assessment) [2].

Compared with the environmental impact assessment of early phase, track planning environmental impact assessment is relatively late which still belongs to the beginning stage. According to a study in the Netherlands in 1998, the percentage conducted tracking on the environmental impact assessment studies is only $16 \%$, and only $6 \%$ post assessment report [3]. However, China has lack of experience in this assessment which is still in the beginning stage. In year 2007, China's ministry of environmental protection's statistics show that in more than 100 industrial park, $40 \%$ of them lack of follow-up supervision, the planning environmental protection countermeasures and measures are hard to be implemented [4]. In order to reduce the unqualified environmental impact assessment documents during the process of construction and operation of the planning project, avoid industrial park making serious environmental pollution and ecological damage during operation [5]. This paper taking Baicheng industrial park as an example to study the trace of planning environment impact assessment, especially focus on large environmental impact industrial park, demonstrates the effectiveness of the environmental protection measures in the industrial park, and then combining the status quo to predict the future development, make the development of the industrial park in the future can be more reasonable.

\section{STUDY AREA AND METHODS}

\section{A. Study area}

Baicheng industrial park (industrial clusters) is located in east longitude $122^{\circ} 25^{\prime}$, north latitude $45^{\circ} 31^{\prime}$ (closely combined with the city Baicheng industrial park is approved by the provincial government for the record of the provincial industrial cluster, accordance with the principle of "overall planning, rolling development" Since May 2005, the city make all efforts to develop this area, which planning area is $22.42 \mathrm{~km}^{2}$ and divided into three phase. The park has been planned according to the functions: planning the agricultural products processing, building materials, machinery, chemical industry, metallurgy, logistics, warehousing and other characteristic industrial district and a residential and commercial services. Commissioned by park in March 2008, Jilin University and Jilin petrochemical design institute wrote the Baicheng industrial park (industrial clusters) regional environmental impact report, and approved by the provincial environmental protection in the same year. 
The enterprises in the park has grown from 31 to 60, these enterprises have been put into production, and there are nearly 40 families under construction enterprises; the functional partition, layout and infrastructure have made adjustments since the period. From the perspective of the environmental impact, these changes will cause certain environmental pressure to the area. Moreover, since Baicheng industrial park finish planning, Track planning environment impact assessment has not been conducted, and environmental protection measures and the forecast for the future have changed comparing with the original EIA planning.

\section{B. Methods}

At present, evaluating track planning environmental impact assessment study method mainly from the following four angles:

1) From the perspective of environmental protection to evaluate :

Through the development of functional areas and construction, atmospheric environment, water environment, sound environment, soil, vegetation and ecological landscape, etc., in the planning environmental impact assessment, conducting monitoring, inspection, statistics, on the various environmental factors, comparing with planning environmental impact assessment of the environmental protection measures to determine its actual amount change. From a perspective of the overall planning after implementation of actual effect comparing with the original forecast the influence of environment, conduct result analysis and evaluation, and further analyzes its reason, predict for the next step Planning and development And the give reasonable suggestion to the planning development and perfection [6].

2) From the perspective of economic development:

First of all, from the micro to analysis land use planning, conduct economic benefit analysis for the actual input and output of the construction of infrastructure and industrial layout. Secondly, from a perspective of the macro, analysis the profit and loss for the effects between economy and the environment interaction, caused by the evaluation object in the object and evaluate the brought by the conduct comparison and analysis for the actual environmental impact, actual economic benefits of the evaluation objects to determine the economic decisions correctly or not [7].

3) From the perspective of the ecological environment: :

The ecological environment is characteristic as holistic, regional, mobility and irreversible features. Industrial Park (Industrial Zone) plan composed by a number of special programs, different planning for the implementation of priorities and target different impact on the ecological environment also have their own advantages and disadvantages [8]. Long-term ecological effects of the implementation of the main analysis plan change on regional ecological environment, affecting terrestrial and aquatic ecosystems, ecological landscape impact. Sustainable lessons, lessons, achieve environmental and ecosystem virtuous cycle and coordination between man and nature, social and economic development [9].

4) From the perspective of planning:
Industrial Park (industrial concentration area) planning is generally inherited the achievements of previous planning and construction, from the regional economy, society, culture, resources, environment and comprehensive transportation society as a whole economic system of strategic, forward-looking, comprehensive and subjective characteristics, considering not only planning itself to the need of the development of social economy, while also taking into account the actual operability, so from the planning point of view of tracking and evaluation most embody the sustainable of [11-12]. Through a comparative analysis on the social and economic system is in park planning and implementation of the actual effect and the expected effect, improvement of quality of life, improve the level of local economy and social stability etc., overall balance of the social benefit, economic benefit and environmental benefit, and optimize the industrial park planning area [13].

This research adopts the planning environmental impact tracking evaluation method for the comprehensive comparison, the first review from the general planning of Baicheng Industrial Park, environmental impact, park environmental management, review the original EIA period and the actual development of the industrial park is different, from the role and influence, effectiveness and efficiency, operation and management aspects of tracking contrast secondly, through analysis, evaluation; now the park development and assessment, control measures focus on the future development of district planning and development direction of pollution, put forward corresponding suggestions and measures, and according to the current intensity of emissions prediction, impact prediction for future planning, that is acceptable; finally, tracking and evaluation conclusions are given in Baicheng industrial park. Compared with, although in the evaluation process slightly rough, and to evaluate the non nuanced, but strong pertinence, avoid the light weight can effectively according to the project planning to make reasonable evaluation of tracking, has higher application value [13].

\section{THE RETROSPECTIVE ASSESSMENT OF BAICHENG INDUSTRIAL PARK}

\section{A. Review and evaluation of regional water environment impact}

According to Baicheng Industrial Park Plan EIA in surface water environmental impact assessment grade, and the area where the existing environment of the, in drainage and discharge area layout of a total of three monitoring sections, the purpose is understanding in Baicheng city life sewage discharge status, understand the downstream receiving water quality and receiving water self purification situation, monitoring sections respectively after the confluence of industrial and sewage drains $0.5 \mathrm{~km}$; life drain sewage ditches in the Industrial Import front $1.0 \mathrm{~km}$ and bearing of the vent area.

Monitoring data evaluation method: using the single standard index of river water quality function to evaluate whether the standard can meet the specified function. The results of the evaluation are shown in Table 1

Evaluation results can be seen, the area before and after the construction of COD, BOD, ammonia nitrogen and SS 
section were increased, which part of the ammonia section increase by a big margin, resulting in the reason is, the EIA, the original period didn't in the sewage treatment plant treatment was directly discharged into the bearing of the vent area, resulting in drainage channels are subject to serious pollution, so monitoring cross section data gaps, pipe network to be continuous improvement and continuous governance East bulla bearing vent area of, the effect of sewage in the region will decrease.

\section{B. Review and evaluation of environmental air environment}

Considering the regional meteorological conditions and Baicheng Industrial Park (industrial concentration area) the functional layout, monitoring of industrial park on the west side, on the east side of TSP, $\mathrm{PM}_{10}, \mathrm{SO}_{2}$ and $\mathrm{NO}_{2}$ factor, the objective to monitor the direction of the dominant wind direction and under the direction of the wind. Evaluation methods: evaluation method using the single standard index method, using monitoring data of each monitoring point, the daily average concentration of various pollutants statistical detection rate, the concentration range, the exceeding standard rate and exceeding the maximum multiple of.

Control before and after air environmental quality assessment results show that the $\mathrm{SO}_{2}, \mathrm{TSP}$ and $\mathrm{NO}_{2}$ concentration decreased may reason for park at the present stage, the monitoring time is non heating period; before and after the current situation of the monitoring period, although there was an increase in the number of the enterprises in the park, but the new increase production with less heat. Therefore, the industrial concentrated area before and after the construction of the environment air quality is not small. The ambient air quality of the regional ambient air quality is good, and the environmental capacity of $\mathrm{SO}_{2}$, TSP and $\mathrm{NO}_{2}$ is evaluated.

\section{Acoustic environment influence review and evaluation}

According to the distribution of the EIA requirements and functional area planning, respectively, in the park in the East, West, north, South and five point noise monitoring, the purpose can effectively understand industrial park and around the sound environment present situation. (Table 1)

From table 3, with the original EIA period monitored noise value, day and night than the original noise increased, due to Baicheng industrial concentration area only started the completion of the area and the second period, moreover due to the operation of the park, car flow also increased, resulting in the regional noise value than the original EIA period of growth. But the area still has good acoustic environment capacity.
TABLE I.

REGIONAL NOISE AND NOISE TEST RESULTS: DB (A)

\begin{tabular}{|c|c|c|c|c|}
\hline \multirow{2}{*}{$\begin{array}{c}\text { Monitoring } \\
\text { point }\end{array}$} & \multicolumn{2}{|c|}{ Original EIA } & \multicolumn{2}{c|}{ Present situation } \\
\cline { 2 - 5 } & Day & Night & Day & Night \\
\hline 1\# & 55.7 & 44.3 & 57.7 & 49.3 \\
\hline 2\# & 46.7 & 43.6 & 47.6 & 45.2 \\
\hline 3\# & 43.3 & 38.6 & 53.2 & 43.5 \\
\hline $4 \#$ & 47.9 & 40.8 & 50.5 & 41.0 \\
\hline $5 \#$ & 53.8 & 44.6 & 61.5 & 50.3 \\
\hline
\end{tabular}

\section{Review and evaluation of environmental impact of solid waste}

According to the development zone plan, solid waste mainly living garbage, coal slag, industrial solid waste, etc. Industrial solid wastes vary according to the industrial structure, and the variety of solid wastes and the amount of production vary greatly. Although the development zone planning has determined the development type of the industrial, but due to into the enterprise also has the very big uncertainty in the future. Therefore, it is difficult to determine the specific future development zone industrial solid waste generation. Baicheng Industrial Park garbage and coal slag raw ring from quantity respectively and 13497t/a 953t/a, present situation respectively and 51840t/a 6132t/a

Comparison of the EIA, the original period and at the present stage, the living garbage and coal slag has obvious growth, according to the plan generated garbage sent to all Baicheng city garbage landfill field uniform processing; slag produced all sold as raw materials, comprehensive utilization.

\section{E. Review and evaluation of landscape environment}

Expected by 2020, urban construction land area will reach $22.42 \mathrm{~km}^{2}$, will gradually reduce the area of farmland, woodland, grassland, and scale of industrial land will be greatly increased, the landscape in the region will be industrial used land, residential land, public facilities, land, municipal facilities, green space, storage sites, road and square, special type. The results of the landscape types in the construction region are shown in Table 2.

TABLE II. THE STATISTICAL RESULTS OF LANDSCAPE TYPES AT THE PRESENT STAGE OF THE CONSTRUCTION AREA

\begin{tabular}{|c|c|c|c|c|}
\hline \multirow{2}{*}{ Block type } & \multicolumn{2}{|c|}{ Original planning } & \multicolumn{2}{c|}{ Actual planning } \\
\cline { 2 - 5 } & $\begin{array}{c}\text { The } \\
\text { measure } \\
\text { of area } \\
\left.\mathbf{( k m}^{2}\right)\end{array}$ & $\begin{array}{c}\text { Percent } \\
\mathbf{( \% )}\end{array}$ & $\begin{array}{c}\text { The } \\
\text { measure } \\
\text { of area } \\
\left.\mathbf{k m}^{2}\right)\end{array}$ & $\begin{array}{c}\text { Percent } \\
\text { (\%) }\end{array}$ \\
\hline Total & 21.5 & 100 & 22.4 & 100 \\
\hline Industrial land & 20.17 & 93.8 & 18.57 & 82.9 \\
\hline $\begin{array}{c}\text { Commercial } \\
\text { land }\end{array}$ & 0 & 0 & 0.92 & 4.1 \\
\hline $\begin{array}{c}\text { Infrastructure } \\
\text { land }\end{array}$ & 0.12 & 0.56 & 0.24 & 1.1 \\
\hline Storage land & 1.21 & 5.6 & 0.24 & 1.1 \\
\hline $\begin{array}{c}\text { Landscape } \\
\text { green / Park }\end{array}$ & 0.3 & 0.14 & 2.43 & 10.8 \\
\hline
\end{tabular}




\section{DEVELOPMENT FORECAST OF BAICHENG INDUSTRIAL PARK}

\section{A. Park Development Forecast}

\section{1) Development target:}

The development of economic and urban construction is the important way to improve the urban system, the two complement each other. China has joined the WTO, economic globalization accelerated, actively participate in social division of labor and cooperation, strengthen internal and external economic links, to market oriented, make full use of the advantages of ecological agriculture, resources, food production, Baicheng industrial park built in urban and rural economic prosperity and social stability, functions clear, and beautiful ecological environment of development zone.

2) Function positioning:

According to the overall plan of Baicheng City, Baicheng city will take full advantage of the outstanding geographical advantages, the industry with new building materials, agricultural and sideline products processing and energy industry. The processing of agricultural and sideline products mainly to the local resources, mainly corn, rice, licorice, red bean, peanut, castor bean, sunflower and other grains and beans. Baicheng development of large-scale agricultural and sideline products deep processing enterprises as a leader can drive farmers to grow large areas, the establishment of adequate production of raw materials base. Industrial Park should also be a solid industry, the development of emerging pollution-free industries.

\section{B. Forecast of pollutant emissions after planning and Implementation}

Through of the park planning development and environmental status review and evaluation can be seen, increase the number of park at the present stage of development with the original EIA period the number of enterprises, although there are conducive to the future development of the zone, but subsequent also increases the regional emissions of pollutants. Therefore, this paper in view of the existing situation of park of water pollutants, air pollution, noise, solid waste emissions to predict

1) Water pollutant discharge forecast:

Baicheng industrial park existing enterprises and in the construction, the proposed enterprise to the water supply and drainage forecast results (Table 3).

From the table can be seen, main products of enterprises in the industrial park for agricultural products processing, building materials and machinery processing and chemical, building materials, machinery processing only a small part of the need to water production, pollutants in wastewater with COD and ammonia nitrogen mainly. The design and treatment scale of the wastewater treatment plant in Baicheng is $50000 \mathrm{~m}^{3} / \mathrm{d}$, the scale of the forward design is $100000 \mathrm{~m}^{3} / \mathrm{d}$, and the processing requirement is met.
TABLE III. FORECAST OF WATER SUPPLY AND DRAINAGE IN BAICHENG INDUSTRIAL PARK

\begin{tabular}{|c|c|c|c|c|c|c|}
\hline \multirow{2}{*}{ Nature } & \multicolumn{2}{|c|}{$\begin{array}{c}2012 \\
\left(\text { million } \mathrm{m}^{3} / \mathrm{a}\right)\end{array}$} & \multicolumn{2}{|c|}{$\begin{array}{c}2015 \\
\left.\text { (million } \mathrm{m}^{3} / \mathrm{a}\right)\end{array}$} & \multicolumn{2}{|c|}{$\begin{array}{c}2020 \\
\left.\text { (million } \mathrm{m}^{3} / \mathrm{a}\right)\end{array}$} \\
\hline & $\begin{array}{l}\text { Water } \\
\text { supply }\end{array}$ & $\begin{array}{l}\text { Drain } \\
\text { pot }\end{array}$ & $\begin{array}{l}\text { Water } \\
\text { supply }\end{array}$ & $\begin{array}{l}\text { Drain } \\
\text { pot }\end{array}$ & $\begin{array}{l}\text { Water } \\
\text { supply }\end{array}$ & $\begin{array}{l}\text { Drain } \\
\text { pot }\end{array}$ \\
\hline $\begin{array}{l}\text { Industrial } \\
\text { area (1) }\end{array}$ & 316.4 & 253.1 & 584.2 & 467.4 & 776.3 & 621.1 \\
\hline $\begin{array}{l}\text { Industrial } \\
\text { area (2) }\end{array}$ & 262.1 & 209.7 & 272.8 & 218.2 & 509.2 & 407.4 \\
\hline $\begin{array}{l}\text { Residential } \\
\text { residents }\end{array}$ & 0 & 0 & 116.93 & 93.5 & 233.9 & 187.2 \\
\hline Public green & 3.68 & 0 & 5.02 & 0 & 5.02 & 0 \\
\hline Total & 582.2 & 462.8 & 979.0 & 779.1 & 1524.4 & 1215.7 \\
\hline
\end{tabular}

\section{2) Air pollutant emission forecast:}

According to the survey, the park is applying for centralized heat; the park will focus on heating in 2015 to replace the existing scattered boiler room.

TABLE IV. FORECAST OF AIR POLLUTANT IN BAICHENG INDUSTRIAL PARK

\begin{tabular}{|c|c|c|c|}
\hline & 2011 & 2015 & 2020 \\
\hline $\begin{array}{l}\text { Boiler } \\
\text { tonnage } \\
(\mathrm{t} / \mathrm{h})\end{array}$ & $\begin{array}{c}\text { Scattered } \\
\text { boiler }\end{array}$ & 120 & 160 \\
\hline $\begin{array}{c}\text { Coal } \\
\text { consumption } \\
\text { (t/a) }\end{array}$ & 259720 & 172800 & 230400 \\
\hline $\begin{array}{l}\text { Pollutant } \\
\text { generating } \\
\text { capacity } \\
\text { Smoke } \\
\text { (t/a) }\end{array}$ & 7072 & 25950.0 & 34500 \\
\hline $\mathrm{SO}_{2}$ & 1870 & 1382.4 & 1843.2 \\
\hline $\mathrm{NO}_{\mathrm{x}}$ & 1164 & 483.8 & 645.1 \\
\hline $\begin{array}{c}\text { Pollutant } \\
\text { discharge } \\
\text { concentratio } \\
\text { n Smoke } \\
\left(\mathrm{mg} / \mathrm{m}^{3}\right)\end{array}$ & 94.5 & 150 & 150 \\
\hline $\mathrm{SO}_{2}$ & 225 & 320.0 & 320.0 \\
\hline $\mathrm{NO}_{\mathrm{x}}$ & 280 & 280 & 280 \\
\hline
\end{tabular}

Therefore, this study combined the status quo, the existing Baicheng Industrial Park air pollutant emissions and subsequent development forecast. Its air pollutant discharge is in Table 4 . The table shows, the boiler soot emission concentration to meet the standard requirements of the "boiler air pollutants emission standard", the class of the second zone 2 hours $/ \mathrm{m}^{3}$, the concentration of $\mathrm{SO}_{2}$ emissions meet the standard $900 \mathrm{mg} / \mathrm{m}^{3}$.

3) Noise environment influence forecast:

The main noise source in the development zone is the traffic noise and the mechanical noise of the industrial enterprises. Development Zone Road Network Structure of the mixed type, according to the natural terrain by grid and free hybrid form, district planning road classification to three levels: trunk roads, the roads and slip roads. Road traffic noise and traffic volume, speed, vehicle type and distance from the road, and other factors, this paper takes the park future road after all the forecast evaluation. 
Forecasting results can be seen, the district planning roads completed and opened to traffic, traffic noise within $25 \mathrm{~m}$ both daytime or night more than 2 standard class district; diurnal traffic noise in the $50 \mathrm{~m}$ outside to less than $60 \mathrm{~dB}$ (a), night in the 50m outside can lower than 50 $\mathrm{dB}$ (a), with noise environmental standards.

4) Solid waste emissions forecast:

The industrial park of solid waste is divided three types, park employees to produce garbage, coal-fired boiler slag and industrial solid waste. Industrial solid waste produced according to the industrial structure of different solid waste of the varieties and quantity have great difference, although the development zone planning to determine the development of the industrial type, but due to into the enterprise also has the very big uncertainty in the future, it is difficult to determine the specific future development zone industrial solid waste generation. Its future park development of solid waste generated forecast see Table 5, the park in the future development and expansion of the number of enterprises, life garbage and slag generated by an increasing trend.

TABLE V. Park DEVELOPMENT OF SOlid WASTE GENERATED

\begin{tabular}{|c|c|c|c|}
\hline Nature & $\mathbf{2 0 1 1}(\mathbf{t} / \mathbf{a})$ & $\mathbf{2 0 1 5}(\mathbf{t} / \mathbf{a})$ & $\mathbf{2 0 2 0 ( t / a )}$ \\
\hline $\begin{array}{c}\text { Living } \\
\text { garbage }\end{array}$ & 4380 & 7446 & 13999 \\
\hline Slag & 77916 & 51840 & 103680 \\
\hline $\begin{array}{c}\text { Industrial } \\
\text { solid waste }\end{array}$ & - & - & - \\
\hline
\end{tabular}

\section{CONCLUSION AND PROSPECT}

In order to make the park in the future development of more reasonable and feasible, it is recommended to the metallurgical zone and agricultural product processing zone planning and adjustment; at the same time, the proposed new district, new energy industry zone.

According to the before and after comparison of the data shows that, area ambient air quality is generally good, the construction of the new enterprises in the park and implementation makes the environment air quality declined slightly, park should be realized as soon as possible within the park central heating; after the scene investigation measured, the noise in the Park value than the original EIA noise slightly increased, but did not cause the phenomenon of noise nuisance; regional water environmental capacity is poor, COD, BOD, ammonia nitrogen and SS section were increased, but with the formal operation of sewage treatment plant, to meet the industrial park in the future sewage treatment; forecast, in the waste treatment plant processing capacity to meet the future development of the park. The three phase of the park, to complete the construction of the water pipe network and other infrastructure before the enterprise admission. Such as the future need, the park should apply for self built sewage treatment plant or expand the existing capacity of Baicheng sewage treatment plant.

Because of the research in the field of collecting information and investigation, some enterprises do not suspend production during winter, so it has not been involved in the economic aspects of the Industrial Park tracking evaluation. When the conditions are ripe, the perfect planning environmental impact tracking evaluation system will be build.

\section{REFERENCES}

[1] T. Zhicheng, "Research of environmental impact assessment in industrial park planning-case study of the environmental impact assessment in mingyang industrial park planning”[D]. Guangxi University. Nanning, 2008.

[2] L. Jing-cun, "Environment-Preserving Problem \& Countermeasures InIndustrial Zone” [J]. North Environment, vol. 4, 2005, pp. 3-4.

[3] Arts . EIA Follow-up: on the role of ex post evaluation environmental impact assessment [M]. Groningen: Geo Press, 1998, 535-544.

[4] H. Ai-bing, B. Cun-kuan, J. Da-he, "Progress in P ractice and TheoreticResearch of Environmental Impact Assessment Followup” [J]. Sichuan Environment, vol.29, 2010, pp. 91-96.

[5] W. Misu, "The significance and function of environmental impact assessment in the environmental impact assessment" [J]. Environment. vol. 9, 2007, pp. 6-7.

[6] W. Ching, M. Mingxia, Q. Wei. "Preliminary study on the environmental impact tracking of comprehensive planning in Huaihe River Basin ” [J]. ZHILI, vol. 1, 2005, pp. 16-17.

[7] Z. Yiting, "A Theory Study on the Following Evaluation of the Reg iona l Plann ing EIA” [J]. Pollution Control Technology. vol. 21, 2008, pp. 15-17.

[8] Y. Yanhong, "Research of Planning Environmental Mpact Tracking Assessment of Lugu Lake Scenic Area” [J]. Northern Environment, vol. 21, 2010, pp. 45-50.

[9] C. Fengxian, "Thesis and Case Study on Regional Planning Environmental Impact following Assessment” [D]. Beijing University of Chemical Technology. Beijing, 2008.

[10] W. Zhigang, "Strategic Environmental Assessment (SEA) and case study of urban planning” [D]. Zhongshan University. Guangdong, 2007.

[11] L. Jun, H. Da-ju, "Overview on the Indicator and Methods of Environmental Impact Assessment for Planning” [J]. Pollution Control Technology, vol. 19, 2006, pp. 26-27.

[12] Z. Yinglie, G. Ru, "Preliminary study on the impact of the planning environment on tracking and assessment" [J]. Environmental Pollution \& Control, vol. 31, 2009, pp. 84-88.

[13] F. Danchen, "Preliminary Environmental Impact Assessment System” [J]. Journal of Shanxi Politics and Law Institute for Administrators, vol. 24, 2011, pp. 26-28. 